\title{
PRS Korea 2017 \& 2018: How to organize an International Plastic Surgery Congress and how to make it more attractive
}

\author{
Jong-Woo Choi
}

Chairman of the Academic Affairs Committee, Korean Society of Plastic and Reconstructive Surgeons (KSPRS) Department of Plastic and Reconstructive Surgery, University of Ulsan College of Medicine, Seoul, Korea

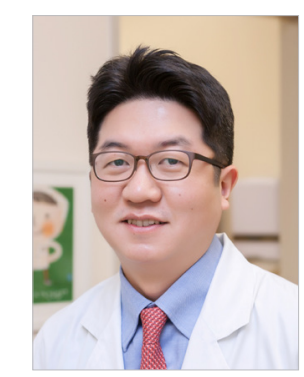

Department of Plastic and Reconstructive Surgery, University of Ulsan College of Medicine, Seoul, Korea

The Korean Society of Plastic and Reconstructive Surgeons (KSPRS) was established in 1966. Since then, it has held an annual national congress, mostly to provide a venue for plastic surgeons in South Korea to share knowledge and experience. The Korean plastic surgery industry received worldwide recognition since the 2000s due to its role in developing original surgical techniques and concepts for Asian patients, and the 50th anniversary congress of the KSPRS was a major success based on the international congress format. In 2017, when preparing the 75th Annual Congress of the KSPRS, the tasks of the chairman of the Academic Affairs Committee included how to maintain this impact for the upcoming congress and how to make the congress more attractive. The organizers of many plastic surgery-related congresses seem to face similar challenges.

First, the number of the nationwide speakers is limited. Moreover, the panelists and their topics tend to be similar each year, making it increasingly difficult to attract the interest of potential participants. Second, financial limitations of the society hinder sending invitations to renowned faculty from overseas. Third, the official language of the congress remains a huge obstacle to international participation. Most national congresses are conducted in the country's native language because the majority of the expected participants are domestic professionals. If English is used as the official language, the number of domestic participants is likely to drop, and the presentations and discussions become much more complicated. We needed to solve these problems to make our PRS Korea Congress internationally attractive. To overcome these obstacles, we reorganized the congress and introduced new programs. In this article, I will share our experiences with these changes.

\section{HOW TO ORGANIZE AN INTERNATIONAL PLASTIC SURGERY CONGRESS}

\section{Official congress language}

Despite numerous objections, we decided to hold the PRS Korea Congress in English. This choice was necessary to make it a truly international event. To overcome problems related to language, for each session, we designated an official English translator who also served as the moderator. Despite our concerns, the presentations and discussions in English yielded acceptable outcomes.

\section{Limited funding}

When organizing an international congress, financial considerations are an extremely important issue. A realistic approach for inviting international speakers was to waive the registration fee with or without support for accommodations. Given the limited budget, financial support for airfare was not possible for so many international speakers, with the exception of some special lecturers. Fortunately, we were able to recruit a number of international speakers with this approach. During PRS Korea 2017, more than 70 international faculty members were invited, which hugely contributed to the success of the event.

\section{Guest society and guest country}

Last year, we invited the Taiwan Society of Plastic Surgeons (TSPS) as the guest society. As the KSPRS has a long-standing friendly relationship with the TSPS, it was a very good decision. Communication between the two societies is continuing to improve. 


\section{Homepage and brochure}

Although we provided a homepage in English, the brochure for Korean plastic surgeons was printed in Korean. Despite our attempts at internationalization, we believe that the brochure in Korean helped create a smoother experience for many attendees. This required investing additional effort in the form of Korean-language editing, but it turned out to be worthwhile.

\section{HOW TO MAIKE A PLASTIC SURGERY CONGRESS MORE ATTRACTIVE}

As chairman of the scientific committee, I worked diligently to find ways to make PRS Korea more attractive to participants. Many issues, including the limited number of confirmed speakers, the yearly similar topics, and the too specialized sessions that attracted few participants, needed to be overcome. Consequently, we needed to suggest new scientific programs that were rather different from the conventional ones. Many brand-new programs were tried.

\section{High-impact presentation sessions}

First, in order to overcome the limited number of speakers, we chose impactful abstracts from free papers that were evaluated by the scientific committee to be presented in high-impact sessions. Traditionally, many free paper sessions attract a limited audience despite the relatively high quality of the presentations. High-impact presentation sessions were allocated between each panel session in the main rooms to allow the presentations to be shared with a larger audience. As this practice continues, we expect that more impactful free papers will be submitted because these presentations can be shared with a much wider audience.

\section{Master class}

Instructional courses had previously been mostly allocated to early-morning sessions. As a result, the number of participants was very limited. In addition, as most instructional courses required an additional payment, very few participants registered. To solve this problem, our master class sessions were allocated to the 'prime time' sessions in the main room, with no need for additional payment. This strategy was very successful. The master class sessions were designed for sharing up-to-date surgical skills and experts' philosophies in each field, unlike instructional courses that mostly deal with basic educational subjects.

\section{Joint sessions}

In joint sessions, experts in each field, such as eyelidplasty, rhinoplasty, facial contouring surgery, and mammoplasty, came together in one session and discussed the diverse surgical options available in that field, in contrast to specific sessions. Moreover, international speakers discussed the commonalities and differences in the concept of beauty and surgical trends in various countries in these joint sessions.

\section{Sessions on beauty}

In order to make the congress feel like a coherent whole, its main theme is very important. However, creating a consistent theme is difficult due to the unique traits of plastic surgery, such as the existence of diverse areas of reconstructive and aesthetic plastic surgery. These sessions addressed the concept of beauty in each subfield of plastic surgery. Thus far, congresses or symposia related to plastic surgery mostly deal with surgical skills. However, given the fact that the ultimate goal of plastic surgery is to create beautiful and ideal shapes, discussions about what would be called a beautiful eye, nose, facial contour, or breast would appear to be necessary. Sessions on the concept of beauty were scheduled as the first session in all specific session groups.

\section{Resident "Golden Bell"}

Residents are an important component of international congresses. However, as many congresses mostly deal with advanced topics, residents can sometimes feel out of place. To engage them more, this session was intended to mimic a popular Korean quiz show for students named "Golden Bell.” The response was overwhelmingly positive. It was a joyful competition about knowledge in surgery in which residents from different subfields of plastic surgery participated. This year, we launched new programs for residents, including a microanastomosis tournament battle and resident debate sessions.

\section{Microanastomosis tournament battle}

This session was conducted as an actual tournament of microsurgical skills based on the time of completion and proper technique in our Research and Reconstruction Forum (R\&R Forum). It was designed to attract the attention of young plastic surgeons and to motivate them to hone their microsurgical skills. About 30 residents competed and showcased their microsurgical skills on artificial vessels. It was a huge success and gained the attention of many residents. The overall feedback was overwhelmingly positive.

\section{Resident debate session}

In this session, a chairman participated, as well as panelists consisting of all the residents. They debated about memorable cases they had encountered during their training. Seven teams joined this session. Their cases were shared in advance to allow them to prepare for the discussion. The performance of the panelists 
and that of the session chairman surpassed our expectations. We expect that this kind of session will inspire residents and provide them with new opportunities.

\section{Internationalization of sessions of each academic association}

The KSPRS consists of 14 academic associations, including the Asian Blepharoplasty Forum, Seoul Rhinoplasty Forum, and academic associations for stem cell and fat or craniofacial, aesthetic facial bone surgery, hand, perforator, facial trauma, minimal invasive surgery, Botox \& filler, breast, anti-aging, hair, and laser. Many academic associations within our society are becoming internationalized through our congress. It is my hope that PRS Korea Congress will be the primary local festival for each academic association that also connects them internationally.

A congress for doctors serves as a festival for sharing knowledge and experience, as well as friendship. To maximize these goals, organizers should keep in mind that scientific programs should be made for the purpose of achieving these goals, and should contribute to the development of techniques and con- cepts. As the world requires endless innovations, congresses in the field of plastic surgery should evolve as well. I hope that this editorial will be helpful to organizers who deal with similar tasks and are trying to overcome the numerous obstacles encountered in planning international congresses.

\section{NOTES}

\section{Conflict of interest}

No potential conflict of interest relevant to this article was reported.

\footnotetext{
Correspondence: Jong-Woo Choi Department of Plastic and Reconstructive Surgery, Asan Medical Center, University of Ulsan College of Medicine, 88 Olympic-ro 43-gil, Songpa-gu, Seoul 05505, Korea

Tel: +82-2-3010-3604, Fax: +82-2-476-7471, E-mail: pschoi@amc.seoul.kr

I appreciate the support and the leadership of Dae-Hyun Lew, the chairman of our society, Seung-Ha Park, the president of our society and thanks for the help of Dr. Hyun-Suk Suh, Dong-Won Lee and the members of academic affairs committee.

Received: 1 Jun 2018 • Revised: 26 Jun 2018 • Accepted: 2 Jul 2018 pISSN: 2234-6163 • elSSN: 2234-6171

https://doi.org/10.5999/aps.2018.00661 • Arch Plast Surg 2018;45:205-297
} 